\title{
O impacto socioeconômico gerado pela fumicultura na microrregião geográfica de Prudentópolis-PR
}

\author{
Zaqueu Luiz Bobato*
}

\section{Resumo}

Este artigo destaca a importância da produção de fumo na microrregião geográfica de Prudentópolis no Estado do Paraná. Sendo assim, apresenta-se um levantamento de dados que permitem ao leitor compreender a dimensão socioeconômica do segmento na microrregião. Também integra este estudo o enfoque sobre a ratificação da Convenção-Quadro para Controle do Tabaco (CQCT). Por fim, aponta-se a necessidade de se pensar políticas públicas alternativas para os produtores que tem o cultivo de fumo como principal meio de sobrevivência.

Palavras-chave: Fumicultura; Convenção Quadro; Propostas alternativas.

The socioeconomic impact generated by tobacco culture in the microregion geographical of Prudentópolis-PR

\section{Abstract}

This paper outlines the importance of tobacco production in Prudentópolis city, geographical area located in Paraná state. Therefore, it presents a survey of data which allow the reader to understand the socioeconomic segment in this micro region. Also, part of this study focus on Tobacco Control Framework Convention (CQCT) ratification, and finally, it points to the

Universidade Estadual do Centro-Oeste (Unicentro). Doutorando em Geografia (UFPR). Mestre em Geografia (UEPG). Graduado em Geografia (Unicentro) campus de Irati-PR. Professor do curso de Geografia da Unicentro campus de Irati (zaqueudegeo@gmail.com).

Geosul, Florianópolis, v. 28, n. 55, p 31-54, jan./jun. 2013 
BOBATO, Z.L. O impacto socioeconômico gerado pela fumicultura ...

necessity of considering alternatives public policies for farmers which have the tobacco production as the principal survival mean. Key words: Tobacco production, Framework Convention, Alternative bids.

\section{Introdução}

A atividade fumageira vem nos últimos anos tendo expressivo destaque na pauta de exportações brasileiras, sobretudo na região sul do país. O cultivo do fumo tem sido uma importante fonte de renda para milhares de famílias que possuem pequenas propriedades, ou seja, que dispõem de pouca terra destinada a plantio.

Atualmente o Brasil é o segundo maior produtor mundial de tabaco e líder em exportações. Dados disponibilizados pelo SindiTabaco (2012) apontam que o cultivo da planta está presente em 704 municípios do Sul do país, envolvendo mais de 187 mil famílias de agricultores, totalizando um número de aproximadamente 742 mil pessoas no meio rural e mais 30 mil empregos diretos nas indústrias de beneficiamento.

Os dados do sindicato ainda apontam que nas safras de 2010/2011, os 373 mil hectares plantados, resultaram em 833 mil toneladas do produto, sendo que deste volume, $52 \%$ foram produzidos no Rio Grande do Sul, 30\% em Santa Catarina e 18\% no Paraná. Percebe-se que os dados evidenciam que o cultivo do tabaco também é expressivo dentro do Estado do Paraná, assim sendo o presente estudo realizará um levantamento de dados a fim de identificar o impacto socioeconômico gerado pela atividade fumageira na microrregião prudentopolitana do Estado.

Explicita-se que o método utilizado na construção do artigo, foi o qualitativo em conjunto com o quantitativo. A utilização do método qualitativo deu-se na revisão da literatura especializada sobre o assunto que foi proposto. Paralelamente ao método qualitativo, o quantitativo possibilitou a constatação de números que evidenciam a produção do tabaco no território da microrregião alvo 
BOBATO, Z.L. O impacto socioeconômico gerado pela fumicultura ...

do estudo. Dando suporte aos métodos destacados, os seguintes procedimentos foram colocados em prática: revisão bibliográfica; consulta de dados em sites oficiais como o do Instituto Brasileiro de Geografia e Estatística (IBGE) e Instituto Paranaense de Desenvolvimento Econômico e Social (Ipardes) entre outros.

\section{A fumicultura na microrregião geográfica de Prudentópolis}

A microrregião que é objeto deste estudo é composta pelos municípios de Guamiranga, Imbituva, Ipiranga, Ivaí, Prudentópolis, Teixeira Soares e Fernandes Pinheiro (IPARDES, 2012).

Figura 01: Área de abrangência da microrregião geográfica de Prudentópolis-PR.

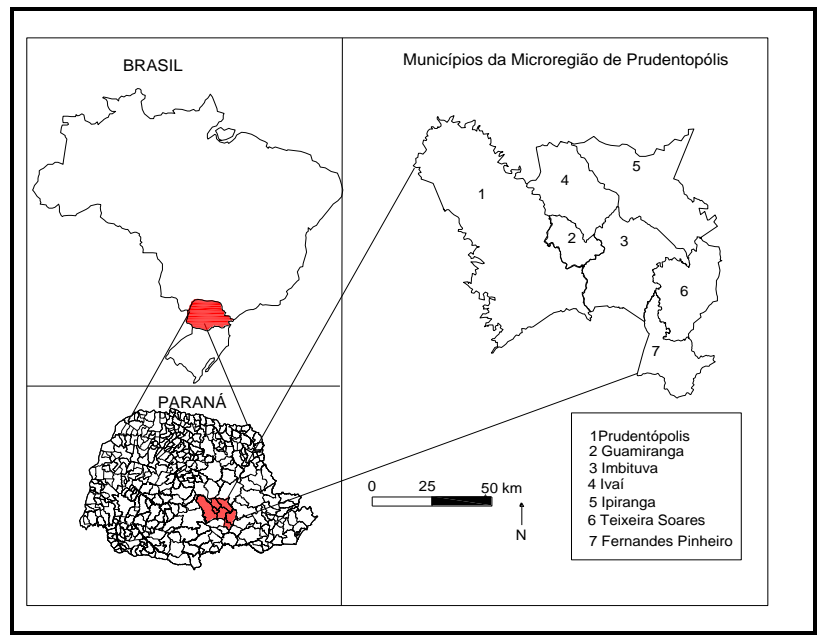

Org. BOBATO, Zaqueu Luiz e ANTONELI, Valdemir (2013).

A microrregião acima destacada passou a intensificar o cultivo do fumo nas pequenas propriedades familiares a partir de 1980 com os descendentes de imigrantes italianos, poloneses, alemães e ucranianos. Consequentemente o fumo passou a ser o 
BOBATO, Z.L. O impacto socioeconômico gerado pela fumicultura ...

principal produto agrícola dos municípios que compõem a microrregião. As áreas rurais produtoras de fumo na microrregião em questão, constituem um território que é produto do processo histórico e geográfico de sua constituição e organização.

Para Silveira (2011), a territorialização da fumicultura na microrregião possui uma estreita relação com o processo histórico e geográfico de consolidação e organização do seu todo territorial, pois a estrutura fundiária resultante do processo de colonização do território microrregional configurou pequenas propriedades que passaram a praticar um modo de produção baseado no trabalho familiar.

Dados do Ipardes (2013) evidenciam que a área do território microrregional soma $6.090,311 \mathrm{~km}^{2}$, abarcando uma população de 129.917 habitantes. Percebe-se nos dados disponibilizados pelo Ipardes que o cultivo de fumo é expressivo nos municípios que compõem o território microrregional. Aponta-se que os dados estatísticos referentes aos seis municípios da microrregião que serão apresentados a seguir, os mesmos foram obtidos a partir dos escritos atualizados no final do ano de 2012 pelo Ipardes nos "Cadernos Estatísticos municipais" do Estado.

O município de Guamiranga possuía no ano de 2010 uma população de 7.900 habitantes (IBGE, 2013), sendo 2.236 moradores da área urbana e 5.664 da área rural. Os dados contidos no Ipardes (2012a) evidenciam que o município é predominantemente agrícola tendo a fumicultura como principal produto dinamizador de sua economia, seguido pelo cultivo de soja, milho e feijão. Observa-se no gráfico 01 que o cultivo do fumo é o que ocupa menos área em hectares (ha) de terra no município, sendo 3.226 ha utilizados para o cultivo da planta. Já a soja ocupa 6.450 ha, o milho 4.100 e o feijão 2.510. No entanto o gráfico 02 permite observar que o fumo ao ocupar menos área de terra para seu cultivo, o mesmo é o que mais gera valor em reais em meio aos outros cultivares agrícolas. 
BOBATO, Z.L. O impacto socioeconômico gerado pela fumicultura ...

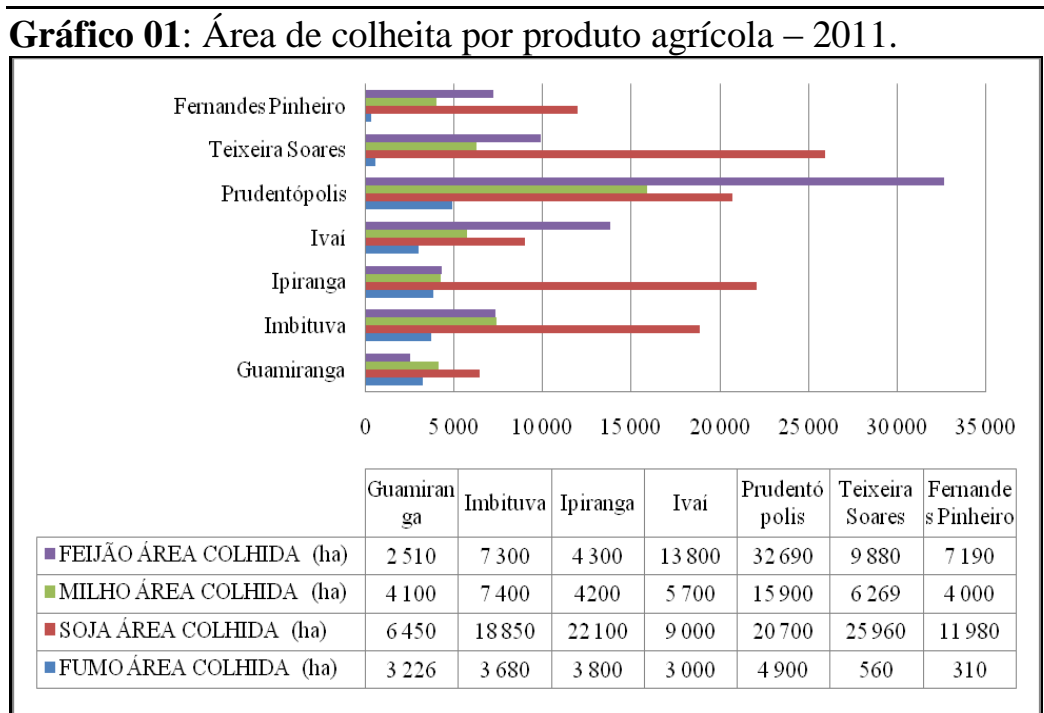

Fonte: Ipardes (2012). Cadernos Municipais. Org. BOBATO, (2013).

Gráfico 02: Valor em R\$ por produto agrícola - 2011.

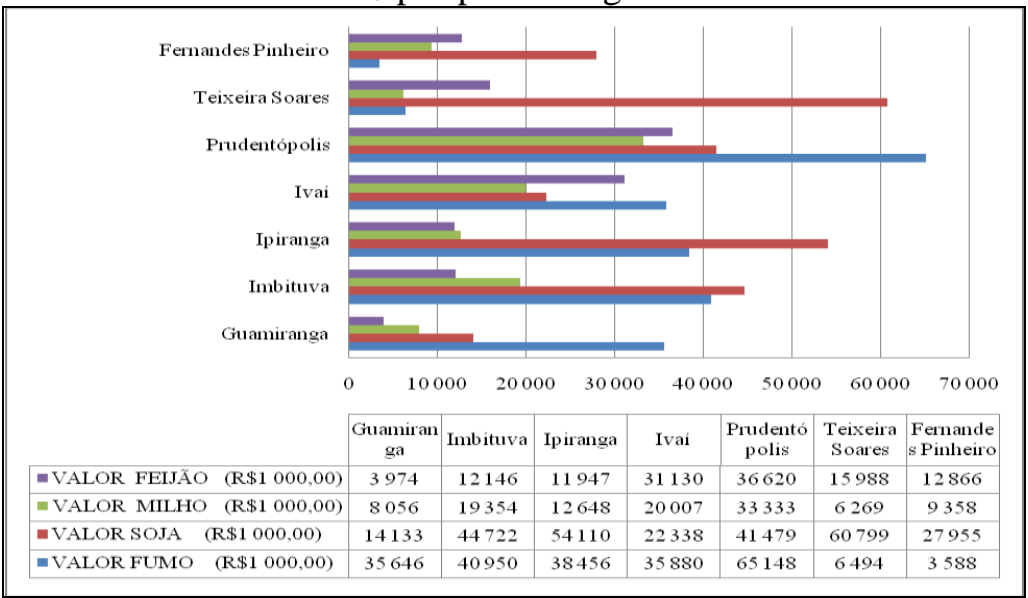

Fonte: Ipardes (2012). Cadernos Municipais. Org. BOBATO, (2013) 
BOBATO, Z.L. O impacto socioeconômico gerado pela fumicultura ...

Tabela 01: Demais produtos agrícolas cultivados no território de Guamirana - 2011.

\begin{tabular}{|l|c|c|c|c|}
\hline \multicolumn{1}{|c|}{ Produtos } & Área colhida & Produção & Rendimento & Valor \\
\hline & $(\mathrm{ha})$ & $(\mathrm{t})$ & $\begin{array}{c}\text { Médio } \\
(\mathrm{kg} / \mathrm{ha})\end{array}$ & $(\mathrm{R} \$ 1000,00)$ \\
\hline Cebola & 89 & 2003 & 22506 & 1001 \\
\hline Batata-inglesa & 56 & 1441 & 25732 & 864 \\
\hline Trigo & 580 & 1508 & 2600 & 663 \\
\hline Mandioca & 100 & 1900 & 19000 & 437 \\
\hline Erva-mate (folha verde) & 170 & 850 & 5000 & 289 \\
\hline Uva & 24 & 168 & 7000 & 201 \\
\hline Pêssego & 13 & 78 & 6000 & 170 \\
\hline Arroz & 100 & 198 & 1980 & 85 \\
\hline Alho & 3 & 14 & 4667 & 63 \\
\hline
\end{tabular}

Fonte: Ipardes (2012a). Caderno Estatístico Município de Guamiranga. Org. BOBATO, (2013).

Na tabela acima é possível visualizar que o cultivo de produtos alternativos ao tabaco, a soja, milho e feijão, possuem pouca expressão, sendo cultivados em pequena escala. Também percebe-se que o valor gerado para cada produto é pequeno, logo sendo pouco rentável para os produtores. Portanto, no momento é a fumicultura, a soja, o milho e o feijão que predominam no município.

No caso do território municipal de Imbituva no ano de 2010 este contava com uma população de 28.455 habitantes (IBGE, 2013), sendo que 17.888 habitavam o meio urbano e 17.567 o rural do município.

Os dados contidos nos gráficos 01 e 02 mostram que a agricultura do município tem o cultivo da soja ocupando maiores quantidades de terras em ha (18.850), seguida pelo milho (7.400 ha), feijão (7.300 ha) e por último o fumo (3.680 ha). Observa-se que no caso do município em questão a lavoura de fumo é a que ocupa menos área no território para ser cultivada.

Salienta-se que o cultivo de soja para ser rentável ao produtor, necessita de maiores quantidades de área, logo, na 
BOBATO, Z.L. O impacto socioeconômico gerado pela fumicultura ...

maioria dos casos são os produtores que possuem acima de 20 hectares de terra que cultivam a planta. Já nas pequenas propriedades o cultivo de soja é inviável, restando o fumo, pois mesmo ocupando pouca terra para plantio permite uma rentabilidade satisfatória (gráfico 01 e 02). Contudo, a fumicultura apesar de ser o produto que ocupa menos ${ }^{1}$ área para ser cultivado, o mesmo só perde para a soja em matéria de lucratividade (gráfico 02).

Tabela 02: Demais produtos agrícolas cultivados no território de Imbituva - 2011.

\begin{tabular}{|l|c|c|c|c|}
\hline \multicolumn{1}{|c|}{ Produtos } & Área colhida & Produção & Rendimento & Valor \\
\hline & $(\mathrm{ha})$ & $(\mathrm{t})$ & $\begin{array}{c}\text { Médio } \\
(\mathrm{kg} / \mathrm{ha})\end{array}$ & $(\mathrm{R} \$ 1000,00)$ \\
\hline Alho & 4 & 17 & 4250 & 76 \\
\hline Arroz & 190 & 394 & 2074 & 169 \\
\hline Batata-Inglesa & 386 & 11718 & 30358 & 7030 \\
\hline Caqui & 3 & 21 & 7000 & 31 \\
\hline Cebola & 240 & 5305 & 22104 & 2652 \\
\hline $\begin{array}{l}\text { Erva-Mate (folha } \\
\text { verde) }\end{array}$ & 350 & 1295 & 3700 & 440 \\
\hline Laranja & 10 & 200 & 20000 & 50 \\
\hline Maçã & 4 & 82 & 20500 & 98 \\
\hline Mandioca & 120 & 2400 & 20000 & 552 \\
\hline Uva & 15 & 168 & 11200 & 201 \\
\hline
\end{tabular}

Fonte: Ipardes (2012b). Caderno Estatístico Município de Imbituva. Org. BOBATO, (2013).

Analisando a tabela acima, visualiza-se que produtos alternativos ao cultivo de soja, milho, feijão e tabaco, são tímidos no território. Portanto, fica evidenciado a importância de se pensar projetos, políticas públicas que fomentem a diversificação, sobretudo em pequenas propriedades onde o cultivo do fumo é intenso.

${ }^{1}$ Em apenas três hectares de terra é possível cultivar a lavoura de fumo obtendo uma renda considerável. 
BOBATO, Z.L. O impacto socioeconômico gerado pela fumicultura ...

No que concerne ao território do município de Ipiranga, no ano de 2010 este tinha um total de 14.150 habitantes (IBGE, 2013). O total de habitantes dividia-se da seguinte forma: 4.889 pessoas residiam no contexto urbano e 9.261 no rural do município. $\mathrm{O}$ território municipal de Ipiranga contendo a maior parte de seus habitantes no meio rural tem o cultivo de soja seguido pelo de feijão, milho e por último o fumo, como os produtos que mais ocupam áreas de terras em hectares no município. Assim como nos municípios já abordados, chama atenção o fato de mesmo sendo o fumo o produto que ocupa menos área, o mesmo é o segundo que mais gera valores, perdendo apenas para a soja no caso deste município. No entanto, reitera-se que o fumo é cultivado sobretudo por agricultores familiares na pequena propriedade. Portanto, tal cultivo é de grande importância para a dinâmica econômica e social do município.

Tabela 03: Demais produtos agrícolas cultivados no território de Ipiranga - 2011.

\begin{tabular}{|l|c|c|c|c|}
\hline \multicolumn{1}{|c|}{ Produtos } & Área colhida & Produção & Rendimento & Valor \\
\hline & $(\mathrm{ha})$ & $(\mathrm{t})$ & $\begin{array}{c}\text { Médio } \\
(\mathrm{kg} / \mathrm{ha})\end{array}$ & $(\mathrm{R} \$ 1000,00)$ \\
\hline Amendoim & 5 & 5 & 1000 & 9 \\
\hline Arroz & 40 & 72 & 1800 & 32 \\
\hline Aveia & 450 & 1160 & 2578 & 464 \\
\hline Batata-inglesa & 80 & 2400 & 30000 & 960 \\
\hline Caqui & 2 & 22 & 11000 & 22 \\
\hline Cebola & 8 & 40 & 5000 & 15 \\
\hline Cevada & 1300 & 4680 & 3600 & 2574 \\
\hline Mandioca & 104 & 1560 & 15000 & 546 \\
\hline Tangerina & 3 & 45 & 15000 & 31 \\
\hline
\end{tabular}

Fonte: Ipardes (2012c). Caderno Estatístico Município de Ipiranga. Org. BOBATO, (2013).

Os dados expressos na tabela acima apontam que a realidade do município de Ipiranga não se difere muito da realidade dos municípios abordados anteriormente, pois, visualiza-se que os 
BOBATO, Z.L. O impacto socioeconômico gerado pela fumicultura ...

produtos alternativos ao cultivo daqueles que mais geram valores no território, são pouco expressivos, exceto o trigo. Porém, o cultivo do trigo esbarra na questão de ter maiores quantidades de terra para que o mesmo possa ser cultivado gerando uma boa rentabilidade.

No que diz respeito ao território municipal de Ivaí, este em 2010 possuía 12.815 habitantes (IBGE, 2013), sendo 4.629 do meio urbano e 8.186 do meio rural. No município em questão a maior parte da população vive no meio rural, o que torna a atividade agrícola, a principal fonte de renda para as famílias.

O gráfico 01 revela que o cultivo de feijão (13.800 ha), seguido pelo de soja (9.000 ha), milho (5.700 ha) é que ocupam maiores quantias de hectares de terras no município, porém vê-se que é o cultivo do fumo (3.000 ha) que tem maior impacto no território, dado o valor que a produção obtém (35.880,00 reais), mesmo ocupando menor área de cultivo.

Tabela 04: Demais produtos agrícolas cultivados no território de Ivaí - 2011.

\begin{tabular}{|l|c|c|c|c|}
\hline \multicolumn{1}{|c|}{ Produtos } & Área colhida & Produção & Rendimento & Valor \\
\hline & $(\mathrm{ha})$ & $(\mathrm{t})$ & $\begin{array}{c}\text { Médio } \\
(\mathrm{kg} / \mathrm{ha})\end{array}$ & $(\mathrm{R} \$ 1000,00)$ \\
\hline Arroz & 40 & 76 & 1900 & 38 \\
\hline Aveia & 100 & 261 & 2610 & 104 \\
\hline Cana-de-açucar & 4 & 140 & 35000 & 8 \\
\hline Caqui & 1 & 4 & 4000 & 3 \\
\hline Cebola & 8 & 160 & 20000 & 56 \\
\hline Cevada & 55 & 143 & 2600 & 64 \\
\hline Laranja & 1 & 17 & 17000 & 6 \\
\hline Maçã & 1 & 15 & 15000 & 13 \\
\hline Mandioca & 70 & 1050 & 15000 & 577 \\
\hline
\end{tabular}

Fonte: Ipardes (2012d). Caderno Estatístico Município de Ivaí. Org. BOBATO, (2013).

A diversidade de produtos cultivados no território expostos na tabela acima, se caracterizam pouco expressivos tanto em área 
BOBATO, Z.L. O impacto socioeconômico gerado pela fumicultura ...

cultivada como em valores gerados. Tal fato é característica marcante em todos os municípios que compõem a microrregião de Prudentópolis.

Semelhante ao caso de Ivaí, os dados expressos nos gráficos 01 e 02 revelam a situação do município de Prudentópolis que em 2010 contava com uma população de 48.792 habitantes em seu território. Tal população se dividia em 22.463 pessoas vivendo na área urbana e 26.329 na área rural do município.

Os gráficos 01 e 02 expressam claramente a importância do cultivo de tabaco no município prudentopolitano, pois os dados apontam que entre os sete municípios que compõem o território microrregional, o de Prudentópolis tem a maior geração de valores advindos da produção de fumo no território municipal. Como ressalta Kraiczek e Antoneli (2012) o município de Prudentópolis tem uma das maiores pruduções de feijão do país, no entanto, vem perdendo espaço na produção por causa da instabilidade dos preços praticados na sua comercialização, dando assim espaço para o crescimento do cultivo do tabaco, sendo que este último gera valores que superam o cultivo e comercialização do feijão.

Kraiczek e Antoneli (2012) a partir de levantamentos realizados em uma pesquisa sobre a fumicultura no município, afirmam que o cultivo do fumo vem mostrando grande rendimento econômico, o que atrai cada vez mais os agricultores para este ramo, pois sua rentabilidade supera qualquer outra atividade agrícola tradicional da região. Outro fator importante para esses produtores se sentirem atraídos pela fumicultura é a possibilidade de utilizarem pequenas áreas de terra para esse cultivo, deixando assim, disponível o excedente da propriedade rural para exercer atividades econômicas alternativas. Com relação à utilização de pequenas áreas de terra, mesmo os agricultores que não têm propriedade própria podem desenvolver esta atividade, alugando terrenos para o plantio e cultivo.

Os autores acima citados ainda mencionam que o fato de o município de Prudentópolis apresentar uma população maior na área rural, se dá pelas características morfoclimáticas, assim como 
BOBATO, Z.L. O impacto socioeconômico gerado pela fumicultura ...

pela formas de ocupação sobre o território, pois fatores como clima, solo e relevo contribuem para um "atraso" agrícola, além de algumas formas peculiares de uso e ocupação do solo. "A região apresenta um relevo com declividade acentuada sendo desfavorável para a mecanização da agricultura. As áreas agrícolas do município são relativamente pequenas, e a maioria dos agricultores tem sua mão de obra familiar, (...) (CRAICZEK; ANTONELI, 2012, p. 61-62)".

Tabela 05: Demais produtos agrícolas cultivados no território de Prudentópolis - 2011 .

\begin{tabular}{|l|c|c|c|c|}
\hline \multicolumn{1}{|c|}{ Produtos } & Área colhida & Produção & Rendimento & Valor \\
\hline & $(\mathrm{ha})$ & $(\mathrm{t})$ & $\begin{array}{c}\text { Médio } \\
(\mathrm{kg} / \mathrm{ha})\end{array}$ & $(\mathrm{R} \$ 1000,00)$ \\
\hline Abacate & 1 & 25 & 25000 & 42 \\
\hline $\begin{array}{l}\text { Abacaxi (mil } \\
\text { frutos) }\end{array}$ & 3 & 32 & 10667 & 38 \\
\hline Alho & 10 & 25 & 2500 & 112 \\
\hline Amendoim & 14 & 20 & 1429 & 40 \\
\hline Arroz & 650 & 1625 & 2500 & 975 \\
\hline Aveia & 55 & 55 & 1000 & 17 \\
\hline Banana & 1 & 11 & 11000 & 4 \\
\hline Batata-inglesa & 270 & 6840 & 25333 & 3076 \\
\hline Cana-de-açúcar & 26 & 1430 & 55000 & 57 \\
\hline
\end{tabular}

Fonte: Ipardes (2012e). Caderno Estatístico Município de Prudentópolis. Org. BOBATO, (2013).

Observa-se a partir dos gráficos 01 e 02 , e ao confrontá-los com os dados contidos na tabela acima, que no município de Prudentópolis o que predomina realmente é o cultivo de fumo e em seguida o soja e feijão. Já as demais produções provavelmente servem para complementar a renda, assim como para o consumo familiar.

No caso do território municipal de Teixeira Soares no ano de 2010 sua população segundo dados do IBGE (2013), era de 10.283 
BOBATO, Z.L. O impacto socioeconômico gerado pela fumicultura ...

habitantes, sendo que 4.796 habitavam o meio urbano e 5.487 o meio rural do município.

Os dados mostrados nos gráficos 01 e 02 chamam a atenção na medida em que evidenciam ser a atividade da fumicultura a que menos se destaca no território municipal. No ano de 2011 foi plantada uma área de 560 ha de fumo, ao passo que o cultivo de soja totalizou uma área de 25.960 ha, já o feijão 9.880 e o milho 6.269 há (gráfico 01).

Tabela 06: Demais produtos agrícolas cultivados no território de Teixeira Soares - 2011

\begin{tabular}{|l|c|c|c|c|}
\hline \multicolumn{1}{|c|}{ Produtos } & Área colhida & Produção & Rendimento & Valor \\
\hline & $(\mathrm{ha})$ & $(\mathrm{t})$ & $\begin{array}{c}\text { Médio } \\
(\mathrm{kg} / \mathrm{ha})\end{array}$ & $(\mathrm{R} \$ 1000,00)$ \\
\hline Alho & 2 & 8 & 4000 & 36 \\
\hline Arroz & 200 & 420 & 2100 & 180 \\
\hline Aveia & 220 & 440 & 2000 & 132 \\
\hline Batata-inglesa & 352 & 11491 & 32645 & 6894 \\
\hline Caqui & 1 & 5 & 5000 & 4 \\
\hline Cebola & 59 & 944 & 16000 & 472 \\
\hline Cevada & 600 & 1300 & 2167 & 614 \\
\hline Erva-mate (folha-verde) & 140 & 420 & 3000 & 151 \\
\hline Mandioca & 125 & 2390 & 19120 & 549 \\
\hline
\end{tabular}

Fonte: Ipardes (2012f). Caderno Estatístico Município de Teixeira Soares. Org. BOBATO, (2013).

Percebe-se que no caso do município de Teixeira Soares, é o cultivo da soja (gráfico 02) que gera maior valor $(60.799,000)$. No entanto, ao se observar os dados do censo agropecuário, disponível no Sistema IBGE de Recuperação Automática (SIDRA) ${ }^{2}$, vê-se que no município de Teixeira Soares, as propriedades em grande parte são compostas por áreas acima de 20 hectares, logo permitindo o cultivo de atividades além do fumo, como no caso a soja, o feijão e o milho.

${ }^{2}$ Sistema IBGE de Recuperação Automática (SIDRA). Disponível em: <http://www.sidra.ibge.gov.br/bda/territorio/unit.asp?e=c\&t=1\&p=CA\& $\mathrm{v}=184 \&$ codunit $=3977 \& \mathrm{z}=\mathrm{t} \& \mathrm{o}=4 \& \mathrm{i}=\mathrm{P}>$. Acesso em 30 de abril de 2013. 
BOBATO, Z.L. O impacto socioeconômico gerado pela fumicultura ...

Sendo assim, acredita-se que as características dos produtos cultivados são reflexos da estrutura fundiária que forma o território. Porém, os dados contidos no SIDRA permitem visualizar que algumas dezenas de famílias dispõem de propriedades com menos de 2 hectares, portanto, é de grande importância pensar a territorialização de cultivares agrícolas que permitam renda considerável para tais famílias que possuem pouca terra para plantio, pois como se observa na tabela acima, os produtos alternativos que são cultivados no território possuem baixos índices no que diz respeito a área plantada bem como a valores obtidos.

Por fim, ao buscar compreensão sobre o município de Fernandes Pinheiro que também está inserido na microrregião geográfica de Prudentópolis, constatou-se que este território no ano de 2010 éra composto de acordo com o IBGE (2013) por uma população que totalizava 5.932 pessoas, sendo 2.094 residindo na área urbana e 3.838 na área rural do município.

O caso deste munícipio assemelha-se com o de Teixeira Soares no que diz respeito ao cultivo de produtos agrícolas.

Percebe-se a partir dos dados expostos nos gráficos 01 e 02 que o plantio de soja ocupando uma área de 11.980 ha gerou o valor de mais de 27 milhões de reais, já o cultivo de feijão abarcando uma área de 7.190 ha possibilitou um montante de mais de 12 milhões de reais. $\mathrm{O}$ cultivo de milho ocupou uma área de 4 mil ha totalizando um valor de mais de 9 milhões de reais.

Por fim o cultivo do fumo que teve pouca expressão na dinâmica econômica do território, este fora cultivado em apenas 310 ha de área, gerando um valor de mais de 3 milhões de reais. Contudo, a critério de comparação vê-se que em matéria de rendimento (valor em reais), o cultivo do fumo é vantajoso, isto devido o produto ser cultivado ocupando pouca área, pois se observarmos o caso do milho, o seu cultivo ocupou doze vezes mais a quantidade de área, portanto para ser rentável cultivar produtos fora o fumo, o produtor necessita dispor de maiores quantidades de terras. 
BOBATO, Z.L. O impacto socioeconômico gerado pela fumicultura ...

Tabela 06: Demais produtos agrícolas cultivados no território de Fernandes Pinheiro - 2011.

\begin{tabular}{|l|c|c|c|c|}
\hline \multicolumn{1}{|c|}{ Produtos } & Área colhida & Produção & Rendimento & Valor \\
\hline Alho & $(\mathrm{ha})$ & $(\mathrm{t})$ & $\begin{array}{c}\text { Médio } \\
(\mathrm{kg} / \mathrm{ha})\end{array}$ & $(\mathrm{R} \$ 1000,00)$ \\
\hline Arroz & 2 & 9 & 4500 & 40 \\
\hline Aveia & 280 & 616 & 2200 & 265 \\
\hline Batata-inglesa & 50 & 100 & 2000 & 30 \\
\hline Cebola & 391 & 11950 & 30563 & 7170 \\
\hline Erva-mate (folha verde) & 270 & 6336 & 23467 & 3168 \\
\hline Mandioca & 180 & 1260 & 7000 & 453 \\
\hline Melancia & 65 & 1615 & 19000 & 371 \\
\hline Pêssego & 5 & 180 & 30000 & 162 \\
\hline
\end{tabular}

Fonte: Ipardes (2012g). Caderno Estatístico Município de Fernandes Pinheiro. Org. BOBATO, (2013).

Ao observar os dados da tabela acima, percebe-se que os produtos alternativos ao cultivo de soja, milho, feijão e fumo, são produzidos em pequena escala no município. A partir de análises realizadas mediante os dados do SIDRA $^{3}$, visualiza-se que a configuração econômica do município de Fernandes Pinheiro, se assemelha com as características já elencadas sobre o município de Teixeira Soares no que diz respeito a agricultura. Afirma-se isto, devido o fato de constatar nos dados do SIDRA que grande parte dos estabelecimentos agropecuários configuram-se sendo portadores de mais de 20 hectares de terra, logo, permitindo o cultivo de produtos como soja, milho e outros.

3 Sistema IBGE de Recuperação Automática (SIDRA). Diponível em: $<$ http://www.sidra.ibge.gov.br/bda/territorio/unit.asp?e=c\&t=1\&p=CA\& $\mathrm{v}=184 \&$ codunit $=6993 \& \mathrm{z}=\mathrm{t} \& \mathrm{o}=4 \& \mathrm{i}=\mathrm{P}>$. Acesso em 15 de abril de 2013. 
BOBATO, Z.L. O impacto socioeconômico gerado pela fumicultura ...

\section{Convenção-quadro para controle do tabaco (CQCT): possíveis reflexos na microrregião de Prudentópolis}

Os autores Silva e Ferreira (2006, p. 01) ao procurarem compreender a importância do cultivo de tabaco ${ }^{4}$ no Brasil, os mesmos afirmam que:

O fumo [tabaco] vem se destacando como um dos principais produtos da pauta de exportações brasileiras, principalmente na região sul do país, onde ele é o terceiro produto mais exportado. Além disso, ele tem sido uma importante fonte de renda para milhares de famílias, principalmente as que possuem pequenas propriedades, representando uma cultura que possui um retorno bastante superior a outras culturas.

Corrobora-se com os escritos acima ressaltados, pois, pesquisas exploratórias em materiais disponibilizados pelo IBGE e Ipardes acerca da microrregião de Prudentópolis que se encontra no sul do Brasil, evidenciam que o cultivo de tabaco é realizado, sobretudo por pequenos agricultores familiares, sendo que estes geralmente possuem pequenas propriedades, logo, pouca terra disponível para plantio.

Vê-se que a atividade é de grande valia para a microrregião prudentopolitana, porém, é preciso levar em consideração que a fumicultura no Brasil vem nos últimos anos enfrentando intensos debates no meio político e acadêmico no sentido de direcionar medidas restritivas, já que o país assinou a "Convenção-Quadro" que prevê o controle do uso do tabaco, controle este adotado pelos países membros da Organização Mundial de Saúde (OMS).

Mengel e Diesel (2009) clarificam que ao longo da história foram lançadas muitas críticas ao uso e produção do tabaco, mas em geral, elas tiveram pouca repercussão política. Contudo, em meados do século XX o controle do tabagismo passa a ser discutido internacionalmente, de maneira global, e em 1999, no

4 No território da microrregião geográfica utiliza-se com maior intensidade o termo "fumo", ou "fumicultura" ao invés de tabaco. 
BOBATO, Z.L. O impacto socioeconômico gerado pela fumicultura ...

âmbito da OMS, decide-se encaminhar à elaboração um tratado internacional para o controle do tabaco.

Segundo Bonato (2007) no ano de 1999 houve a 52 Assembléia Mundial da Saúde, sendo que nesta os países membros das Nações Unidas propuseram a adoção do primeiro tratado internacional de saúde pública da história da humanidade: a Convenção-Quadro para o Controle do Tabaco (CQCT). Destacase que foram mais de quatro anos de elaboração do documento. No ano de 2003, adotou-se o documento por unanimidade pelos 192 Estados-Membros da OMS, durante a 56 $6^{\mathrm{a}}$ Assembléia Mundial da Saúde. Os autores Mengel e Diesel (2009) salientam que com o estabelecimento da CQCT a OMS procura enfrentar um problema de saúde pública de alcance mundial, pois o tabaco se faz presente na escala global, logo a estratégia de controle transcende níveis nacionais, assim sendo:

El CMCT OMS se elaboró en respuesta a la globalización de la epidemia de tabaquismo. La propagación de esa epidemia se ve favorecida por diversos factores complejos con efectos transfronterizos, entre ellos la liberalización del comercio y las inversiones extranjeras directas. Otros factores tales como la comercialización a nivel mundial, la publicidad transnacional del tabaco, la promoción y el patrocinio, así como el tráfico internacional de cigarrillos de contrabando y falsificados también han contribuido al espectacular aumento del tabaquismo. Desde el primer párrafo del preámbulo, que declara que las Partes en ese Convenio "están determinadas a dar prioridad a su derecho de proteger la salud pública", el CMCT OMS marca una tendencia mundial (OMS, 2005, p.v APUD. MENGEL E DIESEL 2009, p. 232).

Silva e Ferreira (2006, p. 08) salientam que a Convenção-Quadro para o controle do tabaco "trouxe uma série de medidas, muitas delas já em vigor no Brasil, e que podem no longo prazo impactarem de forma negativa na demanda pelo fumo". Clarifica-se que o objetivo principal da Convenção-Quadro é o de preservar as gerações presentes e futuras 
BOBATO, Z.L. O impacto socioeconômico gerado pela fumicultura ...

das consequências sanitárias, sociais, ambientais e econômicas do consumo e da exposição à fumaça do tabaco.

O autor Bonato (2009) em seus escritos aponta que a Convenção-Quadro resultou em obrigações aos países que assinaram o tratado, para tanto, estes possuem a missão de implementarem importantes medidas como:

- Redução da demanda por tabaco: aplicação de políticas tributárias e de preços; proteção contra a exposição à fumaça do tabaco em ambientes fechados; regulamentação dos conteúdos e emissões dos produtos derivados do tabaco; divulgação de informações relativas a estes produtos; desenvolvimento de programas de educação e conscientização sobre os malefícios do tabagismo; proibição da publicidade, promoção e patrocínio; implementação de programas de tratamento da dependência de nicotina.

- Redução da oferta de produtos do tabaco: eliminação do contrabando; restrição ao apoio e aos subsídios relativos à produção e à manufatura do tabaco.

- Proteção ao meio ambiente: na implementação da Convenção, as partes devem observar a proteção da saúde das pessoas e do meio ambiente.

- Responsabilidade civil: inclusão das questões de responsabilidade civil e penal nas políticas de controle do tabaco, bem como estabelecimento das bases para a cooperação judicial nessa área.

- Cooperação técnica, científica e intercâmbio de informações: elaboração de pesquisas nacionais relacionadas ao tabaco e seu impacto sobre a saúde pública; coordenação de programas de pesquisas regionais e internacionais; estabelecimento de programas de vigilância do tabaco; cooperação nas áreas jurídica, científica e técnica (BONATO 2009, p. 15).

Tais medidas ao serem paulatinamente adotadas podem refletir econômica e socialmente no território da microrregião de Prudentópolis, já que esta tem a atividade de plantio de fumo como meio para sobrevivência de centenas de famílias que vivem em 
BOBATO, Z.L. O impacto socioeconômico gerado pela fumicultura ...

pequenas propriedades, e muitas destas famílias não possuem fonte de renda além da do cultivo do fumo.

Faz-se importante frisar que o tratado da Convenção-Quadro no Brasil, foi aprovado pelo plenário do Senado Federal em 27 de outubro de 2005. No entanto, a aprovação do tratado gerou polêmica por parte da sociedade que tem a atividade do cultivo da planta como fonte de renda, bem como de sindicatos que atuam junto aos produtores no país.

De acordo com Bonato (2009, p. 15-16 grifos do autor):

O tratado começou a se tornar polêmico a partir da ofensiva do Sindicato das Indústrias do Fumo do RS e das publicações na imprensa por parte da Afubra (Associação dos Fumicultores do Brasil), com informações sobre supostas implicações negativas da ratificação da Convenção para a economia nacional. Em função da pressão por parte das indústrias e de algumas representações de agricultores, o Senado Federal promoveu diversas audiências públicas, em Brasília, na Bahia e nos três estados da região Sul.

Em meio às discussões contrárias a ratificação do tratado, várias organizações da sociedade civil como a Rede de Tabaco Zero, a Sociedade Brasileira de Oncologia e a Sociedade Brasileira de Pneumologia, contando com o apoio do Poder Executivo por meio da Casa Civil, assim como dos Ministérios da Saúde, do Desenvolvimento Agrário, das Relações Exteriores, da Agricultura e da Fazenda, lutaram no sentido de haver a ratificação da Convenção-Quadro, fato que ocorreu em 27 de outubro de 2005. A ratificação se deu, sobretudo, pelos altos índices de mortes constatados no país e no mundo, dado o consumo do produto.

Souza (2009) ressalta em sua pesquisa que o Instituto do Câncer estima que mais de 30 milhões de brasileiros fumam, e que em todo mundo esse número chega a 1,3 bilhão. O SindiTabaco coloca que são consumidos anualmente cerca de 140 bilhões de cigarros no Brasil. Sendo assim, a OMS aponta que o tabagismo é a principal causa de morte evitável em todo o mundo. Desta forma, 
BOBATO, Z.L. O impacto socioeconômico gerado pela fumicultura ...

a CQCT com apoio da OMS objetiva diminuir os danos sanitários e sociais decorrentes do cultivo e uso do produto. A Convenção fixa padrões internacionais para o controle do tabaco, prevendo:

adoção de medidas relacionadas à propaganda e patrocínio, política de impostos e preços, rotulagem, ao comércio ilícito e ao tabagismo passivo, a dependência da nicotina, além de cooperação nas áreas científica, educacional e sanitária, dentre outras. É, portanto, composta por iniciativas intersetoriais e abrangentes, e tem como objetivo principal à preservação das gerações presentes e futuras das conseqüências sanitárias, sociais, ambientais e econômicas do consumo e da exposição à fumaça do tabaco (ORGANIZAÇÃO MUNDIAL DE SAÚDE, 2005 APUD SOUZA 2009, p. 02).

As medidas estipuladas pela CQCT podem gerar impactos implicando em mudanças, tanto nos hábitos dos fumantes quanto no circuito produtivo do fumo no Brasil e no mundo.

A produção de tabaco no país podendo ou não entrar em "decadência", não deixa de lado questões que envolvem problemas que são de cunho social, já que é comprovado que o consumo do produto pela via do cigarro ocasiona graves danos à saúde tanto dos fumantes, como também de quem cultiva o produto, devido à alta exposição aos agrotóxicos utilizados na lavoura. Desta maneira, é de extrema importância pensar projetos por meio de políticas públicas que visem propiciar alternativas para os pequenos produtores.

A discussão em torno de políticas públicas visando auxiliar a transição de produção alternativa ao do tabaco é parte integrante das propostas desdenhadas na Convenção, é o que aponta Bonato (2009, p. 16), pois segundo ele tal preocupação está refletida nos artigos 4 e 17, e no Preâmbulo da Convenção, que dizem o seguinte:

Artigo $4^{\circ}$, parágrafo $6^{\circ}$ : Devem ser reconhecidos e abordados, no contexto das estratégias nacionais de desenvolvimento sustentável, a importância da assistência técnica e financeira para auxiliar a transição econômica dos produtores agrícolas e trabalhadores cujos meios de vida sejam gravemente afetados em decorrência dos programas de controle do tabaco, nas 
BOBATO, Z.L. O impacto socioeconômico gerado pela fumicultura ...

Partes que sejam países em desenvolvimento, e nas que tenham economias em transição. Artigo 17: As partes, em cooperação entre si e com as organizações intergovernamentais internacionais e regionais competentes promoverão, conforme proceda, alternativas economicamente viáveis para os trabalhadores, os cultivadores e, eventualmente, os varejistas de pequeno porte. Preâmbulo: Conscientes das dificuldades sociais e econômicas que podem gerar a médio e longo prazo, os programas de controle do tabaco em alguns países em desenvolvimento ou com economias em transição, e reconhecendo suas necessidades por assistência técnica e financeira no contexto das estratégias de desenvolvimento sustentável formuladas no nível nacional.

Bonato (2009) acredita que a médio e longo prazo o impacto da redução de consumo sobre a produção nacional ocorrerá. No entanto, como escreve o autor "ao se reconhecer os impactos que a redução do consumo trará no longo prazo sobre a demanda de produção, a preocupação com a busca de alternativas economicamente viáveis não pode aguardar a efetivação dos efeitos para a busca de soluções e alternativas, principalmente para o elo frágil da cadeia produtiva, os fumicultores (BONATO 2009, p. 16)”.

Não se pode esquecer que segundo dados do Ministério do Desenvolvimento Agrário-MDA, 97\% da produção advinda do cultivo de tabaco provêm da agricultura familiar, ou seja, esta atividade representa uma importante fonte de renda para os pequenos agricultores, em especial aqueles com menos de um módulo rural, tendo em vista que esta atividade possibilita uma boa rentabilidade por área, quando comparado à outras culturas.

A realidade acima exposta é parte do que se presencia na microrregião de Prudentópolis, pois o cultivo do tabaco é praticado, sobretudo por pequenos agricultores que dispõem de pouca terra para cultivar o produto que os garante renda para sobreviverem. Portanto, é de extrema importância que as políticas públicas que visem propiciar alternativas de renda para os pequenos produtores 
BOBATO, Z.L. O impacto socioeconômico gerado pela fumicultura ...

sejam propostas e pensadas, por conseguinte, as políticas locais necessitam angariar projetos colocando-os em prática.

\section{Considerações finais}

O artigo realizado levantou dados que apontam a importância socioeconômica que a atividade fumageira tem para a microrregião geográfica de Prudentópolis-PR. Constatou-se que em todos os municípios estudados dentro da microrregião prudentopolitana, o cultivo do fumo mostrou-se importante por resultar em dinâmicas econômicas nos territórios municipais, além é claro de permitir a sobrevivência de centenas de famílias que dispõem de pequenas propriedades, na qual a prática da agricultura familiar prevalece. Percebeu-se a partir dos levantamentos de dados que no território microrregional as alternativas de cultivos fora a do fumo são poucas, caracterizando-se tímidas, fato este que reforça a importância da atividade fumageira para as famílias que dispõem de pouca terra para plantio, pois no momento atual as alternativas de diversificação manifestam-se com pouca intensidade.

Mediante as constatações que revelam a necessidade de estabelecer projetos que propiciem alternativas de renda para os pequenos produtores, enfatiza-se que é condição sine qua non que os governos do âmbito municipal, estadual e federal fomentem e direcionem propostas para os segmentos sociais que possuem apenas a atividade fumageira como meio de obtenção de renda. Propostas, mas também verbas, para que novas experiências de cultivos alternativos ao fumo sejam territorializados aos poucos, para que consequências de cunho econômico e social não ocorram prejudicando centenas de famílias que vivem no território da microrregião geográfica de Prudentópolis no Estado do Paraná.

Elucida-se que a realização deste artigo permitiu a constatação de um "leque" de problemas, aguçando assim, a dar continuidade em pesquisas no segmento produtivo do fumo, assim como nas questões que envolvem a prática de "reconversão de atividades" dado os resultantes da CQCT, portanto, novos projetos de estudos serão 
BOBATO, Z.L. O impacto socioeconômico gerado pela fumicultura ...

apresentados e executados, pois percebeu-se a necessidade de o meio acadêmico/científico compreender e revelar a complexidade da cadeia produtiva do tabaco, que tem em seu meio questões de cunho social, político, econômico, ambiental e cultural. Assim sendo, acredita-se que compreender e divulgar as pesquisas feitas nestes municípios pode contribuir para que projetos de cultivos alternativos ao do tabaco sejam postos nos territórios, e isto certamente resultará em benefício, sobretudo para os pequenos agricultores que neles estão inseridos histórica e geograficamente.

\section{Referências bibliográficas}

BONATO, Amadeu A. A Fumicultura no Brasil e a ConvençãoQuadro para Controle do Tabaco. DESER - Departamento de Estudos Sócio-Econômicos Rurais. Curitiba, Janeiro de 2007.

Conjuntura: Fumo/ A fumicultura e a ConveçãoQuadro Desafios para a Diversificação. DESER - Departamento de Estudos Sócio-Econômicos Rurais. Curitiba, outubro de 2009.

IBGE. Instituto Brasileiro de Geografia e Estatística. Disponível em: $\quad\langle$ http://www.ibge.gov.br/cidadesat/topwindow.htm?1>. Acesso em 15 de abril de 2013.

Ipardes. Instituto Paranaense de Desenvolvimento Econômico e Social. Perfil da Microrregião Geográfica de Prudentópolis, 2012. Disponível em: <http://www.ipardes.gov.br/perfil_regioes/ MontaPerfilRegiao.php?Municipio $=443 \& b t O k=o k>$. Acesso em 13 de janeiro de 2013.

- Caderno Estatístico Município de Guamiranga.

Dezembro de 2012a. Disponível em: $<$ http://www.ipardes.gov.br/cadernos/Montapdf.php?Municipio $=8$ 4435\&btOk=ok $>$. Acesso em 10 de fevereiro de 2013.

Dezembro de 2012b. Disponível em:


BOBATO, Z.L. O impacto socioeconômico gerado pela fumicultura ...

$<$ http://www.ipardes.gov.br/cadernos/Montapdf.php?Municipio=8

$4430 \& b t O k=o k>$. Acesso em 10 de fevereiro de 2013.

Caderno Estatístico Município de Ipiranga.

Dezembro de 2012c. Disponível em: <http://www.ipardes.gov.br/ cadernos/Montapdf.php?Municipio $=84450 \& \mathrm{btOk}=\mathrm{ok}>$. Acesso em 10 de fevereiro de 2013.

. Caderno Estatístico Município de Ivaí. Dezembro de 2012d. Disponível em: <http://www.ipardes.gov.br/cadernos/ Montapdf.php?Municipio=84460\&btOk=ok>. Acesso em 10 de fevereiro de 2013.

- Caderno Estatístico Município de Prudentópolis.

Dezembro de 2012e. Disponível em: <http://www.ipardes.gov.br/ cadernos/Montapdf.php?Municipio $=84400 \& b t O k=0 k>$. Acesso em 10 de fevereiro de 2013.

- Caderno Estatístico Município de Teixeira Soares.

Dezembro de 2012f. Disponível em: <http://www.ipardes.gov.br/ cadernos/Montapdf.php?Municipio $=84530 \& b t O k=0 k>$. Acesso em 10 de fevereiro de 2013.

Caderno Estatístico Município de Fernandes Pinheiro. Dezembro de 2012g. Disponível em: <http://www.ipardes.gov.br/cadernos/Montapdf.php?Municipio=8 $4535 \& b t O k=o k>$. Acesso em 10 de fevereiro de 2013.

RAICZEK, Tarcizio; ANTONELI, Valdemir. O Avanço do Cultivo do Tabaco no Município de Prudentópolis-PR: ESTUDO DE CASO DA DÉCADA DE 2000. Revista Percurso NEMO. Maringá, v. 4, n. 2, p. 59- 77, 2012. Disponível em: <http://www.periodicos.uem.br/ojs/index.php/Percurso/article/view /16847>. Acesso em 13 de abril de 2013.

MDA. Ministério do Desenvolvimento Agrário. Disponível em: <http://www.mda.gov.br/portal/>. Acesso em 15 de abril de 2012. 
BOBATO, Z.L. O impacto socioeconômico gerado pela fumicultura ...

MENGEL, Alex Alexandre; DIESEL, Vivien. Globalização, Convenção Quadro para o controle do tabaco e as disputas pelos rumos dos territórios fumicultores. Interfaces em Desenvolvimento, Agricultura e Sociedade. Revista IDeAS, v. 3, n. 2, p. 226-255, jul./dez. 2009. Disponível em: <http://r1.ufrrj.br/cpda/ideas/revistas/v03/n02/IDeAS-v03_n02Artigo_ALEX_MENGEL_e_VIVIEN_DIESEL.pdf $>$. Acesso em 12 de setembro de 2012.

SILVA, Sabrina Soares; FERREIRA, Patrícia Aparecida. A fumicultura no Brasil: um estudo exploratório sobre os impactos da Convenção-Quadro para o controle do tabaco e o posicionamento do Governo Federal. XXVI ENEGEP - Fortaleza, CE, Brasil, 2006.

Disponível em: <http://www.abepro.org.br/biblioteca/ENEGEP2006_TR560372_8 720.pdf $>$. Acesso em 26 de junho de 2012.

SILVEIRA, Rogério Leandro L. da. Rede agroindustrial do fumo e a dinâmica de organização espacial e de usos do território na região Sul do Brasil. Relatório do Projeto de Pesquisa - CNPq Edital 03/2008. UNISC, Santa Cruz do Sul, janeiro de 2011.

SINDITABACO. Sindicato Interestadual da Indústria do Tabaco. Disponível em: 〈http://sinditabaco.com.br/>. Acesso em 15 de março de 2012.

SOUZA, Raquel Pereira. Convenção - Quadro para Controle do Tabaco: reflexões sobre o futuro da fumicultura brasileira. Sociedade Brasileira de Economia, Administração e Sociologia Rural. Porto Alegre, 2009. Disponível em: <http://www.sober.org.br/palestra/13/606.pdf $>$. Acesso em: $10 \mathrm{de}$ agosto de 2012 .

Recebido em maio de 2013 Aceito em junho de 2013 